\title{
ARENDT E TOCQUEVILLE E AS POTENCIALIDADES DA AÇÃO COLETIVA
}

\author{
Arendt and Tocqueville and the potential of collective action
}

Rosângela Chaves ${ }^{1}$

\begin{abstract}
RESUMO:
Embora fosse manifesta a admiração de Hannah Arendt pela obra de Alexis de Tocqueville, ela nunca explorou de maneira mais consistente o pensamento dele em seus textos. No entanto, apesar da pouca visibilidade que Arendt confere ao autor da Democracia na América em sua obra, é marcante a afinidade entre os dois autores na forma de pensar a política e as potencialidades da ação coletiva. O artigo começa como uma breve explanação sobre em que aspectos da obra de Arendt, desde Origens do totalitarismo, é possível perceber a influência de Tocqueville, para depois explorar três pontos em que é se pode perceber uma vísivel confluência entre os dois autores: o diagnóstico que apresentam das Revoluções Americanas e Francesa, sobretudo na preocupação de ambos com a desafio da criação e da preservação de instituições livres; a compreensão mútua da liberdade como sinônimo de liberdade política, e a ênfase em formas de autogoverno como as comunas (no caso de Tocqueville) e os conselhos populares (no caso de Arendt), além das associações voluntárias, como caminhos para garantir a participação popular e a experiência da liberdade política.
\end{abstract}

Palavras-chave: Hannah Arendt. Alexis de Tocqueville. Revolução. Liberdade. Ação coletiva.

\begin{abstract}
:
Although Hannah Arendt's admiration for the work of Alexis de Tocqueville was expressed, she never more consistently explored his thinking in her writings. However, despite the little visibility that Arendt confers on the author of Democracy in America in his work, the affinity between the two authors in the way of thinking about politics and the potential of collective action is striking. The article begins with a brief explanation of in which aspects of Arendt's work, from the Origins of Totalitarianism, it is possible to perceive the influence of Tocqueville, and then explore three points in which a visible confluence between the two authors can be seen: the diagnosis that they present from the American and French Revolutions, above all in their concern with the challenge of creating and preserving free institutions; the mutual understanding of freedom as synonymous with political freedom, and the emphasis on forms of self-government such as communes (in the case of Tocqueville) and popular councils (in the case of Arendt), in addition to voluntary associations, as ways to guarantee popular participation and the experience of political freedom.
\end{abstract}

Key words: Hannah Arendt. Alexis de Tocqueville. Revolution. Freedom. Collective action.

\section{Introdução}

É de amplo conhecimento a manifesta admiração que Hannah Arendt nutria por Alexis de Tocqueville (1805-1859), de quem ela exaltava a capacidade de pensar politicamente, ao lado de outros autores que também figuram como seus "heróis", como Maquiavel e Montesquieu. O mérito maior de Tocqueville, para Arendt, era a sua preocupação em não se desviar do real, da concretude do mundo público, elevando a ação política como o principal ponto de apoio de suas reflexões um esforço, aliás, que é vísivel ao longo de toda a obra arendtiana.

\footnotetext{
1 Graduada em Comunicação Social - Jornalismo pela UFG, em Direito pela PUC-GO e em Filosofia Licenciatura pelo Claretiano Centro Universitário. Mestre e doutora em Filosofia pela UFG. Jornalista e professora do curso de Direito da Faculdade Católica de Anápolis (GO). E-mail: rosangelachaves@gmail.com.
} 
No entanto, apesar dessa estreita afinidade com o autor de $A$ democracia na América, Arendt surpreendentemente nunca explorou de maneira mais consistente as ideias dele em seus textos, a exemplo do que fez com os já citados Maquiavel e Montesquieu ou mesmo Rousseau - este, em uma via oposta, alvo de críticas ferozes da autora -, para citar três autores que se ocuparam de questões que também mobilizaram o pensamento tocquevilliano. É verdade que ela cita Tocqueville com alguma frequência, às vezes para referendar um argumento dela própria, raras vezes para discordar de um ponto de vista do escritor francês. Mas, em geral, são referências rápidas, que não penetram no âmago da obra tocquevilliana.

Em que pese a presença modesta de Tocqueville nos escritos de Arendt, as confluências entre os dois autores, entretanto, são marcantes. E essa convergência não se limita à "forma" de conduzir as suas reflexões, tendo como ponto de partida a experiência concreta da política, como se disse acima, nem tampouco à constatação mútua de que as categorias tradicionais da filosofia política já não eram mais suficientes para explicar os desafios da modernidade - constatação expressa por Tocqueville na sua célebre sentença "Como o passado não mais ilumina o futuro, o espírito caminha nas trevas", que aparece no capítulo final do segundo volume de $A$ democracia na América (TOCQUEVILLE, 1992b, p. 850), à qual Arendt volta e meia mencionava, frisando a necessidade evocada por ele do surgimento de "uma nova ciência política para um mundo totalmente novo" (TOCQUEVILLE, 1992a, p. 8). ${ }^{2}$

Além de partilhar com Tocqueville essa premência de buscar novos caminhos para compreender a politica e o tempo presente, Arendt aproxima-se do autor francês no que diz respeito ao "conteúdo" do seu próprio pensamento - por exemplo, na análise que faz de temas como o fenômeno da revolução moderna; a problemática envolvendo a noção abstrata de direitos humanos; a atomização e o conformismo dos indivíduos na sociedade de massa; os despotismos que podem emergir do seio das democracias modernas; a liberdade como sinônimo de ação política, entre outros tópicos de relevância na obra de ambos os autores que recebem um diagnóstico parecido por parte deles.

É difícil datar com precisão quando emergiu o interesse de Arendt por Tocqueville, porém, é certo que, desde a redação de Origens de totalitarismo, na década de 1940, a obra do autor eleva-se como uma das referências da filósofa. Conforme Richard King (2015, p. 90), em 1945, uma nova edição de $A$ democracia na América havia sido lançada nos Estados Unidos. Conjuntamente com um livro que saíra em 1938, de autoria de George W. Pierson, intitulado Tocqueville and Beaumont in America, essa reedição do grande clássico do autor francês devolveu a Tocqueville o posto de um proeminente intérprete da sociedade norte-americana, ao lado de Max Weber. Na década seguinte, o sociólogo Raymond Aron - com quem Arendt mantinha um diálogo intelectual desde a década de 1930 e a quem devotava uma alta estima, apesar das discordâncias entre ambos sobre questões de teoria política (cf. YOUNG-BRUEHL, 1982, p. 104) - "redescobre" Tocqueville

\footnotetext{
${ }^{2}$ A tradução das obras em língua estrangeira citadas ao longo deste texto é de nossa autoria.
} 
na França, em seus seminários na Sorbonne, e classifica o pensador como um dos fundadores da sociologia moderna (ARON, 2011, p. 317).

Em carta ao seu marido Heinrich Blücher, datada de 8 de julho de 1946, Arendt, de férias em Hanover (New Hampshire), conta que estava dedicada à leitura de Tocqueville, ao mesmo tempo em que refletia sobre o tema dos direitos humanos, o qual renderia algumas das páginas mais famosas de Origens do totalitarismo. "Eu leio Tocqueville e Shakespeare e 'mexo' enormemente com os direitos do homem", escreve ela, acrescentando que pretendia "tirar essa história a limpo" (ARENDT, 1996, p. 129). Tanto como Arendt na sua crítica à abstração dos direitos humanos, Tocqueville também havia sido influenciado pela leitura de Burke, ao afirmar, em O Antigo Regime e a Revolução, que o Homem sujeito de direitos, conforme a proclamação da Déclaration des Droits de l’Homme et du Citoyen da Revolução Francesa, era o homem em abstrato, apartado das leis, dos costumes e das tradições de uma comunidade política (TOCQUEVILLE, 2004, p. 61-62).

Todavia, Arendt não faz qualquer menção a Tocqueville na seção sobre os direitos humanos em Origens.... O autor comparece em citações breves em outras passagens da obra, para ilustrar, por exemplo, considerações de Arendt sobre o ódio aos judeus (que alcançou seu clímax na Europa quando estes haviam perdido seu poder, mas não sua riqueza, da mesma forma que, como Tocqueville apontara, ocorrera com os nobres às vésperas da Revolução Francesa); a doutrina racial de Gobineau (de quem Tocqueville fora próximo, embora opositor radical à sua teoria racista ${ }^{3}$ ) e o determinismo histórico (ARENDT, 1973, p. 4; 158; 345).

Em 1955, Hannah Arendt ministrou um curso sobre Tocqueville na Universidade da Califórnia e, nas suas anotações para as aulas, transcreveu diversos trechos de um aclamado livro sobre o autor lançado no final da década de 1930, Prophet of the age - $A$ study of Alexis de Tocqueville, de J. P. Mayer (CANOVAN, 1992, p. 67, nota 16). Nessa obra, Mayer identifica no novo tipo de despotismo que Tocqueville vislumbra no segundo volume da Democracia..., nomeado por ele de "Estado tutelar", uma antecipação dos regimes fascistas do século XX (MAYER, 1939, p. 52). Em 1958, Arendt traz a público $A$ condição bumana, em que Tocqueville ganha uma única referência, mas em uma passagem crucial do livro, na qual a autora trata do conformismo exigido pela sociedade, âmbito no qual a possibilidade de ação política é excluída (ARENDT, 1998, p. 39). Como já apontaram Canovan (1992) e Pitkin (1998), Arendt sem dúvida inspirou-se nas ideias de Tocqueville para desenvolver os temas do conformismo e do isolamento dos indivíduos nas sociedades modernas de massa, que ele trata sobretudo no segundo tomo da Democracia na América e os quais constituem uma das questões centrais de $A$ condição bumana.

Nos anos seguintes, Tocqueville vai merecer um pouco mais de visibilidade em dois textos de Arendt. Em Sobre a revolução, o autor é um dos mais citados pela filósofa - mais de 20 vezes -,

\footnotetext{
${ }^{3}$ Neste sentido, ver a carta de Tocqueville a Gobineau, de 17 de novembro de 1853, na qual ele escrevo: "Ora, eu vos confesso que, depois de vos ter lido tão atentamente quanto antes, eu permaneço situado no extremo oposto de vossas doutrinas. Eu as considero verdadeiramente falsas e certamente perniciosas" (TOCQUEVILLE, 1959, p. 201-204).
} 
embora, novamente, em breves menções, sem ser objeto de uma discussão mais alongada. Todavia, aos leitores da obra tocquevilliana, torna-se patente a forte afinidade com as ideias de Tocqueville ao longo do livro. Conforme já observou Dana Villa (2008, p. 87), pode-se dizer que há uma continuidade temática entre os dois volumes da Democracia... e Sobre a revolução. A descrição de Tocqueville da relativa igualdade social que predominava na democracia norte-americana; a importância das comunas e da experiência de autogoverno; a ação conjunta na forma da livre associação, e a necessidade de uma radical descentralização do poder são temas que ecoam nesse livro de Arendt. E deve-se acrescentar que o diagnóstico sobre o paradoxal despotismo democrático que Tocqueville vê nascer com a Revolução Francesa, com seu culto a um Estado forte e centralizador, conforme ele descreve na Democracia... e em O Antigo Regime e a Revolução, também é reapropriado por Arendt. Por fim, os temores de Tocqueville acerca de uma "tirania da maioria" são reiterados por Arendt nas críticas que ela dirige à opinião pública e ao conceito de Rousseau de vontade geral no seu estudo sobre as revoluções modernas.

O outro texto de Arendt em que as ideias de Tocqueville ganham mais peso é o seu ensaio sobre a desobediência civil, incluído no livro Crises da república. Aqui, Arendt apoia-se nas passagens que Tocqueville escreveu sobre o movimento associativo nos Estados Unidos para defender as potencialidades políticas das associações voluntárias, que ela enxerga como uma força legítima de organização e ação política, a despeito de não se deter na distinção - às vezes também um pouco fluida - que Tocqueville faz entre associações políticas e civis e tampouco admitir, como faz o autor francês, que os partidos políticos possam estar incluídos entre elas.

Após estes breves comentários acerca da presença de Tocqueville na obra arendtiana, serão explorados a seguir três temas em que pode-se perceber uma visível convergência entre Tocqueville e Arendt, conforme apontamos em nossa tese de doutorado (CHAVES, 2018): o diagnóstico de ambos sobre o legado das Revoluções Americana e Francesa, a compreensão mútua da liberdade como sinônimo de ação política, e a aposta nos poderes locais e descentralizados (no caso de Tocqueville, as comunas e, no caso de Arendt, os conselhos populares) e nas associações como espaços privilegiados de ação política.

\section{Revolução e institucionalização da liberdade}

Em um raro momento de discordância com Tocqueville em Sobre a revolução, Hannah Arendt critica o autor francês por ter se demonstrado "curiosamente desinteressado" pela Revolução Americana e por seus artífices (ARENDT, 1990, p. 61). Com efeito, em A democracia na América, Tocqueville preocupa-se mais em abordar a realidade da democracia norte-americana pósrevolução e, no seu $\mathrm{O}$ Antigo Regime e a Revolução, seu objetivo é analisar as causas que levaram ao levante revolucionário de 1789 na França. No entanto, tal como Arendt, ele foi um leitor atento e entusiasta dos escritos dos líderes políticos que lançaram as bases para a fundação dos Estados 
Unidos $^{4}$. E se a Revolução Americana não comparece na obra do autor com o destaque que Arendt julga que merecia, a maneira como a filósofa compreende as revoluções modernas - as quais representam, no seu entendimento, a experiência de um novo início, uma ruptura que implica a fundação de um novo corpo político, sustentado em instituições livres (ARENDT , 1990, p. 34-35) - alinha-se às reflexões de Tocqueville que, no seu estudo sobre a Revolução Francesa, tem como um dos seus objetivos entender por que os revolucionários franceses falharam na sua missão de institucionalização da liberdade pública. ${ }^{5}$

Em outra parte de Sobre a revolução, quando critica a ala da historiografia moderna que nem mesmo considera que os EUA passaram por uma revolução, embora não mencione Tocqueville expressamente, parece evidente que Arendt inclui o autor entre os adeptos dessa corrente historiográfica, justamente por ter deplorado, nas páginas anteriores, o “desinteresse” dele pela Revolução Americana. É certo que, em A democracia na América, Tocqueville insiste em dizer que os EUA não tiveram uma "revolução democrática" como a França (TOCQUEVILLE, 1992a, p. 14). Mas aqui é preciso compreender o sentido dessa expressão "revolução democrática” empregada por ele: o qualificativo "democrática" implica uma revolução não só política, mas também das estruturas sociais, e uma mudança de tal ordem só havia ocorrido na França, com a derrubada do estado social aristocrático; nos Estados Unidos, a revolução havia se limitado à esfera política. Tal entendimento é o mesmo que Arendt expressa em Sobre a revolução. A guerra pela independência norte-americana não representou para ambos os autores uma alteração na ordem social norteamericana, tendo em vista que o estado social democrático dos EUA não foi uma consequência desse evento em particular, mas nasceu com a própria colonização (TOCQUEVILLE, 1992a, p. 1415, ARENDT, 1990, p. 22).

Entretanto, Tocqueville não deixou de ressaltar a importância do significado histórico do segundo momento da Revolução Americana demarcado por Arendt e que ela exalta com tanto vigor: o período de deliberação em torno da Constituição Federal e da sua promulgação, que Tocqueville, assim como Arendt, julga ainda fazer parte dos eventos relacionados à Revolução Americana6. Se o autor não emprega o adjetivo "revolucionário" para qualificar esse

\footnotetext{
${ }^{4}$ Conforme um dos biográficos de Tocqueville, Jean-Louis Benoît, Tocqueville foi um leitor atento e entusiasta de $O$ federalista, a série de artigos publicados por Alexander Hamilton, John Jay e James Madison com argumentos em favor da ratificação da Constituição norte-americano que é também largamente citada por Arendt em Sobre a revolução. Outro grande líder e teórico da Revolução Americana cuja obra mereceu uma leitura atenta de Tocqueville foi Thomas Jefferson (cf. BENOÎT, 2013, p. 202).

${ }^{5}$ Como ele expressa em O Antigo Regime e a Revolução: "Quando o amor dos franceses pela liberdade política despertou, eles já haviam concebido, em matéria de governo, um certo número de noções que não só se colocavam dificilmente em acordo com a existência de instituições libres, mas lhes eram quase contrárias" (TOCQUEVILLE, 2004, p. 194).

6 Como se pode deduzir da leitura do trecho no primeiro volume da Democracia na América, em que Tocqueville - ao comentar o fato de que o novo governo federal norte-americano, encabeçado por George Washington, só ter assumido suas funções em 1789, após o período de dois anos em que a Constituição Federal dos EUA foi debatida e elaborada e depois submetida à aprovação dos estados da federação - afirma o seguinte: "A revolução da América terminou, pois, precisamente no momento em que começava a nossa" (TOCQUEVILLE, 1992a, p. 126).
} 
acontecimento, é certamente porque esse termo está carregado das conotações de mudança radical do ordenamento social, e toda a violência que essa mudança acarreta, tal como ocorrido na França, que Tocqueville lamentava tanto. Mas, se pensada no sentido arendtiano, como o início de algo novo, a palavra "revolução" não soaria como um elemento estranho no léxico tocquevilliano para tratar da relevância histórica da Constituição norte-americana.

Como Arendt faria mais de um século depois, Tocqueville percebeu e destacou a absoluta novidade representada pelo pacto celebrado em torno da Constituição Federal dos EUA. No volume 1 da Democracia na América, quando frisa não haver medida de comparação entre a guerra de independência americana e a Revolução Francesa, o autor ressalta, em contrapartida, que o mais admirável na história dos Estados Unidos, e que se compara em grandeza com a Revolução Francesa, foi o processo de elaboração e ratificação da Constituição Federal do país. Na visão de Tocqueville, esse período de debates em torno da Constituição americana representou algo jamais visto na história mundial (TOCQUEVILLE, 1992a, p. 125). A partir dele, o texto constitucional alcançava um novo status: o de um documento escrito originário do povo, discutido e aprovado por meio de representantes escolhidos livremente em meio à população, que autorizava o estabelecimento de um governo com poderes limitados, ao mesmo tempo em que se impunha como uma barreira à onipotência da vontade popular. ${ }^{7}$

Assim como Tocquevlle, Arendt se vale do exemplo da Constituição norte-americana, apesar de fazer algumas ressalvas, como se verá na seção a seguir, para, como bem apontou Bignotto (2011), enfatizar o papel determinante da constituição no plano simbólico e imaginário da fundação de um novo corpo político. $\mathrm{Na}$ visão da autora, o povo norte-americano fez de sua Constituição o marco inicial e o sustentáculo de sua república. Os revolucionários norte-americanos converteram a noção romana segundo a qual a fundação assenta as bases para a preservação e o aumento do corpo político no entendimento de que é a Constituição que conserva e transmite a autoridade política. Por isso, desde a sua promulgação, ela passou a ser venerada com a "força da religião" - religião aqui no sentido de religare, de se vincular a um início, "assim como a pietas romana consistia em voltar a se vincular ao início da história romana, à fundação da cidade eterna" (ARENDT, 1990, p. 198).

Também com relação à Revolução Francesa, o diagnóstico de Tocqueville e Arendt é coincidente. $\mathrm{Na}$ visão de ambos, a perda de rumos do movimento revolucionário francês ocorreu justamente a partir do momento em que seus líderes e o resto da nação não conseguiram, diferentemente do que havia acontecido nos EUA, estabelecer um pacto em torno de uma

\footnotetext{
7 Tocqueville não é contrário à soberania popular, mas se opõe à ideia de um poder que se apresenta como ilimitado, mesmo que originário do povo, degenerando em tirania. Para ele, o limite à soberania popular deve ser a justiça, daí a sua valorização da Constituição como contrapeso à vontade popular. Em Sobre a revolução, Arendt, por sua vez, ao criticar o conceito de vontade geral de Rousseau e a forma como ele foi apropriado pelos revolucionários franceses, aponta o perigo da ideia de uma vontade popular que se coloca acima das leis e das instituições. Esse tema é longamente discutido por nós em nossa já mencionada tese de doutorado (CHAVES, 2018).
} 
constituição que colocasse fim ao movimento revolucionário e legitimasse as instituições políticas do país, assentadas na liberdade e na igualdade. Premidos pelas circunstâncias a buscar uma solução para a miséria das massas, os revolucionários franceses deixaram de privilegiar o esforço para a criação de instituições estáveis.

Além do mais, a queda da monarquia representou o desmoronamento de toda a estrutura política do país, tendo em vista que a população não estava organizada em corpos constituídos, como os norte-americanos desde a época da colonização, um aspecto que Arendt explora em Sobre a revolução e que também constitui um dos temas da reflexao tocquevilliana sobre a revolução (TOCQUEVILLE, 2004, p. 226-227; ARENDT, 1990, p. 179). Em outras palavras, faltava aos franceses uma tradição de liberdade política que os norte-americanos gozavam desde a experiência colonial. Justamente por lhes faltarem essa tradição, os líderes revolucionários não puderam escapar à tentação de eleger um novo absoluto para colocar no lugar do rei, alçando o povo e a vontade popular acima das leis e das instituições. Mas como o povo francês não estava organizado politicamente, viu-se reduzido à ideia abstrata de nação (ARENDT, 1990, p. 156). Assim, o fracasso da institucionalização da república abriu caminho para uma excessiva centralização do poder, bloqueando o acesso à participação popular, e que desembocou, como acentua Tocqueville, no despotismo democrático da "oligarquia de 1793" (TOCQUEVILLE, 1992a, p. 253) e, na sequência, no império napoleônico.

Nas suas análises sobre o fenômeno revolucionário, é o poder político que se constitui o tema central da reflexão de Tocqueville e Arendt. Como bem acentua Raymond Aron, a concepção tocquevilliana das revoluções é essencialmente política, porque ele as compreende "como a resistência das instituições políticas do passado ao movimento democrático moderno" (ARON, 2011, p. 350). No caso particular da França, na interpretação do autor, a revolução eclode porque as instituições políticas do Antigo Regime, baseadas no privilégio e na exclusão da maior parte da sociedade francesa, veem-se colocadas em xeque pelo avanço do estado social democrático (aqui, leia-se democrático como sinônimo de igualitário), um movimento que, como Tocqueville aponta na introdução do primeiro volume da Democracia, já datava de séculos e compreendia também uma mudança no próprio imaginário, com a disseminação de uma cultura mais igualitária, em que as diferenças e as hierarquias aos poucos vão deixando de ser vistas como um dado natural (TOCQUEVILLE, 1992a, p. 6-7). No entanto, a rejeição de Tocqueville ao que ele chama de “espírito revolucionário francês", principalmente após a ascensão dos jacobinos ao poder, é porque, na premência de impor a igualdade democrática, ele acabou sufocando a liberdade democrática, na sua tarefa de implementar um Estado centralizado que concentrasse toda a ação politica da nação.

Também a reflexão arendtiana sobre as revoluções tem como objetivo perscrutar o estatuto do poder - a sua geração, a sua legitimação e a sua preservação. Conforme salienta Poizat, "para além dos debates historiográficos, Sobre a revolução revela-se, efetivamente, ser o lugar de uma reflexão aprofundada sobre a noção de poder, que nos leva ao coração do pensamento de Arendt" 
(POIZAT, 2013, p. 146). Deve-se compreender a noção de poder aqui como Arendt a recupera da tradição da pólis grega e da civitas romana: como produto da ação conjunta e espontânea de muitos, opondo-se à visão tradicional do poder como domínio, apoiado nos instrumentos da violência (ARENDT, 1972a, p. 135-139). Assim, o que interessa a Arendt quando se debruça sobre o fenômeno revolucionário moderno é pensar sobre a constituição e a preservação de um poder secular resultante da ação política e legitimado por ele, com a criação de um novo corpo político que esteja sustentando por instituições estavéis e duradouras e as quais assegurem a liberdade política e a participação popular.

Em suma, na análise que Tocqueville e Arendt fazem das revoluções modernas, importa a ambos realçar o primado da liberdade, entendida sobretudo como liberdade política, como se verá a seguir.

\section{Liberdade como ação coletiva}

Em um ensaio no qual aponta os débitos de Arendt para com Tocqueville, Margie Lhoyd comenta que a filósofa poderia ser chamada de "liberal de uma nova espécie", da mesma maneira que o autor francês se autoclassificara. Lhoyd justifica seu argumento com base na constatação acertada - de que nos dois autores, ao mesmo tempo em que é comum a ambos, por um lado, uma forte rejeição aos princípios liberais do materialismo individualista e do progresso inevitável, há o endosso, por outro lado, a valores caros ao liberalismo como o direito à propriedade, à liberdade de discurso e de associação, a uma política descentralizadora e à participação política por meio de associações (LHOYD, 1995, p. 37).

Se tal epíteto, no entanto, pode ser aplicado a Arendt - ela que expressava fortes reservas ao liberalismo - é justamente porque suas concordâncias com a corrente liberal no sentido da valorização das liberdades individuais, da preservação da propriedade privada (e não do acúmulo de riqueza, é importante ressaltar) e do associativismo são temperadas por uma concepção de liberdade como sinônimo de ação e participação políticas, tal como em Tocqueville. Mas é exatamente por conceber a liberdade nesse sentido que ambos os autores se distanciam da tradição do liberalismo clássico, que pensam a liberdade como liberdade da política, à qual pensadores liberais como Constant e Berlin relacionam ao domínio de não interferência política em que se poder dar livre curso às liberdades individuais e à livre-iniciativa (CONSTANT, 2016; BERLIN, 1981).

Em Tocqueville, a liberdade pode ser compreendida em três dimensões: a) a ideia da liberdade como independência, equivalente ao sentimento que o indivíduo tem do seu próprio valor; b) a ideia da liberdade como participação política, que valoriza uma cidadania ativa, pela qual os indivíduos exercem efetiva participação nos negócios públicos, e c) a ideia de liberdade associada à igualdade, em que todos são compreendidos como iguais em direito e dignidade, pois Tocqueville reconhecia que, nas sociedades democráticas modernas, já não havia mais espaço para um 
ordenamento social desigual, característico da aristocracia. Essas três dimensões formam uma síntese em que a liberdade é vista não só como um direito do indivíduo, mas também como um dever: dever para consigo mesmo, para com o próximo e para com a comunidade em geral. Assim, ela não é encarada apenas como uma faculdade do indivíduo - mas como um dever tanto moral quanto cívico. ${ }^{8}$

Se é possível delimitar essas três dimensões da liberdade no pensamento tocquevilliano, em várias passagens da sua obra, entretanto, ele se refere à liberdade política como "a liberdade". Isso fica evidente, por exemplo, no prefácio ao Antigo Regime e a Revolução, em que a liberdade é tomada como sinônimo de ação política e é apontada como o único caminho para retirar os indivíduos modernos do isolamento, servindo de obstáculo, dessa forma, à tendência das sociedades igualitárias de acabarem sucumbindo a alguma forma de despotismo político (TOCQUEVILLE, 2004, p. 49-50).

Já para Arendt, a razão de ser da política é a liberdade, "e sem ela a vida política não teria sentido" (ARENDT, 2018, p. 167). No Ensaio sobre a revolução, ela propõe uma distinção entre liberty, que corresponde ao leque de liberdades civis, ou liberdades negativas, as quais formam o conjunto de atividades consideradas não políticas garantidas pelo corpo político aos seus integrantes, e freedom, a liberdade como sinônimo de participação política, de admissão popular na esfera pública, em outras palavras, da ação política coletiva (ARENDT, 1990, p. 32-33). O gozo das liberties não requer necessariamente o exercício da freedom, uma vez que as primeiras, apesar de serem garantidas pela estrutura política, apenas “especificam os limites, não só do governo, mas do âmbito público em si” (ARENDT, 2018, p. 198).

A crítica de Arendt às democracias liberais modernas, com sua ênfase na proteção das liberdades privadas e no bem-estar individual e com o seu frágil ideal de cidadania, é que elas foram incapazes de resistir ao totalitarismo. Daí a preocupação da autora em recuperar a noção de liberdade como freedom, que ressurgiu com as revoluções modernas, mas que deriva da experiência das cidades-Estado gregas, onde a liberdade surgiu como fenômeno político, em uma "forma de organização política na qual os cidadãos viviam juntos na condição de não domínio, sem uma divisão entre govenantes e governados" (ARENDT, 1990, p. 30).

Portanto, pode-se dizer que Tocqueville e Arendt têm em comum uma concepção republicano-democrática da liberdade que, sem desconsiderar a relevância das liberdades individuais, destaca a participação política dos cidadãos. Dessa forma, a liberdade é pensada por ambos não como algo natural do ser humano, mas antes como uma práxis, que só se concretiza no seu exercício. E nos dois autores também são convergentes a valorização de algumas formas de organização popular em que essa liberdade pode ganhar corpo, por meio da ação coletiva, como se verá a seguir.

\footnotetext{
${ }^{8}$ Nesse sentido, ver LAMBERTI, 1983.
} 


\section{Poderes locais e o associativismo}

Conforme se afirmou anteriormente, a concepção de liberdade em Arendt e Tocqueville escapa à tradição liberal que pensa a liberdade como algo exterior à política, ao espaço de não intervenção do Estado sobre as atividades privadas dos indivíduos. Ambos os autores vinculam a liberdade individual à experiência do autogoverno - para Arendt, é no espaço público que os indivíduos se reconhecem como livres e iguais, enquanto, para Tocqueville, a independência individual está estreitamente vinculada à livre participação dos cidadãos nos negócios públicos. Com base na realidade concreta da política, ambos se valeram de experiências históricas no nível das comunas (Tocqueville) e dos conselhos populares (Arendt), além das associações voluntárias, para pensar formas de autogoverno nas quais a experiência da liberdade política possa se materializar.

$\mathrm{Na}$ vida cotidiana das townships norte-americanas, que Tocqueville conheceu de perto durante o seu périplo pelos EUA no início da década de 1830, como descreve na Democracia na América (TOCQUEVILLE, 1992a, p. 64-75), o autor pôde constatar em plena ação uma prática de democracia direta levada coletivamente pelos cidadãos, os quais dispensavam, dentro dos limites da sua comunidade, qualquer tipo de representação política. Todos os assuntos de interesse comum eram decididos em conjunto nas assembleias locais. Para o autor, nesse modelo adotado pela república norte-americana de pulverização do poder, descentralizando-o e disseminando-o por todo o país e conferindo um amplo raio de ação política às localidades, emanava "a força dos povos livres" (TOCQUEVILLE, 1992a, p. 65).

A experiência da ação política também despertava nos moradores das comunas norteamericanas, tal como percebeu Toqueville, um gosto pela vida pública, porque eles sentiam que o poder político não era algo distante deles. Nesse ponto, na ótica do autor, repousava uma das principais virtudes do sistema comunal norte-americano: "disseminar o poder, a fim de tornar as pessoas mais interessadas pela vida pública" (TOCQUEVILLE, 1992a, p. 74). Na sua compreensão, o patriotismo norte-americano manifestava-se, assim, de uma forma que se poderia chamar de "pragmática": ao invés de surgir como um sentimento vinculado a uma imagem idealizada do local a que se pertence, ele se erigia como um culto aos quais os indivíduos aderiam pela prática, porque partilhavam do poder, com todos os direitos e todas as responsabilidades que tal partilha acarretava.

Em Sobre a revolução, Hannah Arendt demonstra-se menos entusiasta do que Tocqueville com o modelo federativo que prevaleceu nos Estados Unidos após a promulgação da sua Constituição Federal, por esta não ter incorporado nenhuma disposição sobre as comunas e as assembleias comunais. Assim, seria uma questão de tempo para que os governos dos Estados e o da União, com o peso de suas diversas atribuições constitucionais, terminassem por enfraquecer as municipalidades. No diagnóstico de Arendt, essa falha criou uma situação paradoxal, em que haveria "menos oportunidade para o exercício da liberdade pública e o gozo da felicidade pública 
na república dos Estados Unidos do que houvera antes nas colônias da América britânica" (ARENDT, 1990, p. 298).

Ao modelo de organização política que acabou se estabelecendo nos EUA, Arendt contrapõe a proposta de sistema distrital (ward system) que Thomas Jefferson, já ao final da vida, passou a defender (ARENDT, 1990, p. 248-255). O projeto de Jefferson previa a divisão dos país em centenas de pequenas repúblicas, cada uma com sua parcela de poder e autonomia, em uma gradação de competências e autoridade que se estenderia desde as comunas, passando pelos condados, pelos Estados até a União, de forma a evitar a centralização do poder e garantir a participação popular na condução dos assuntos públicos.

A forma como Jefferson descreve o funcionamento das suas "repúblicas elementares" aproxima-se muito da descrição de Tocqueville das comunas na Democracia da América - e, de fato, o modelo no qual se inspira Jefferson são as townships da Nova Inglaterra, cuja vida política, à época da visita de Tocqueville em 1830, continuava a todo vapor. ${ }^{9}$ Arendt, no entanto, curiosamente não faz nenhuma referência a Tocqueville quando aborda o sistema distrital jeffersoniano em Sobre a revolução, destacando, entre suas virtudes, a liberdade comunal e a descentralização do poder, precisamente os aspectos que o autor francês mais enaltece nesse modo de organização política. $\mathrm{Na}$ proposta de Jefferson, Arendt enxerga o esboço de uma nova forma de governo - os conselhos populares - assentada em uma base realmente popular, plural e dinâmica, que ela discute ao final do seu ensaio sobre as revoluções setecentistas, também inspirada no exemplo das sociedades populares que emergiram durante a Revolução Francesa, experiência que se repetiria na Comuna de Paris de 1871 e, no século XX, nos räte alemães, nos sovietes da Revolução Russa e nos conselhos populares da Revolução da Hungria (ARENDT, 1990, p. 249).

Quanto às associações, tanto as políticas quanto as civis, estas ocupam na teoria política de Tocqueville um papel de suprema importância para a democracia. No primeiro volume da Democracia..., o autor dedica uma seção inteira às associações políticas (TOCQUEVILLE, 1992a, p. 212-220), entre as quais o autor inclui não só os grupos formados por cidadãos tendo em vista algum objetivo político (e o exemplo histórico do qual se vale é a mobilização nacional contra a tarifa alfandegária que se formou nos EUA em 1831), mas também os partidos políticos e até as comunas. Já no segundo volume, são destacadas as associações civis, cujos objetivos podem ser filantrópicos, culturais, econômicos etc (TOCQUEVILLE, 1992b, p. 620-625). No entanto, não se trata de uma estratégia para colocar em lados opostos o mundo público e a sociedade civil, como se a segunda representasse um campo completamente autônomo em relação ao primeiro, conforme bem apontou Dana Villa (2006, p. 234). Para Tocqueville, há uma interdependência esses dois tipos

\footnotetext{
9 Uma das cartas em que Thomas Jefferson refere-se a esse projeto é a endereçada a John Tyler, em 26 de maio de 1810, que pode ser conferida no site American History - from revolution to econstruction and beyond. 1994-2012. Disponível em: http://www.let.rug.nl/usa/presidents/thomas-jefferson/letters-ofthomas-jefferson/jefl205.php. Acesso em: 28 nov. 2021.
} 
de associação e ambas fomentam uma cultura associativa muito benéfica para a vida democrática como um todo.

$\mathrm{Na}$ perspectiva do autor, as associações são instrumentos importantissimos para a democracia não apenas porque contribuem para descentralizar a administração estatal e o poder político, mas também por constituírem uma ferramenta que capacita os cidadãos ao pleno exercício da liberdade política - lembrando que esta, para ele, assim como para a Arendt, é sempre uma práxis. Além de funcionarem como um antídoto contra o fenômeno do individualismo, por favorecerem a integração social e o desenvolvimento de um sentimento comunitário, as associações representam uma barreira ao despotismo estatal, com sua tendência a monopolizar toda a ação política e a forçar os indivíduos a permanecerem em uma situação de atomização político-social. Por essa razão, Tocqueville denomina a arte da associação como "ciência-mãe" dos países democráticos. "Para que os homens permaneçam ou se tornem civilizados, é necessário que entre eles a arte de se associar se desenvolva e se aperfeiçoe na mesma proporção que a igualdade de condições aumenta" (TOCQUEVILLE, 1992b, p. 625).

Já Arendt, no seu ensaio sobre a desobediência civil, incluído no livro Crises da república, equipara o movimento de desobediência civil desencadeado nos Estados Unidos a partir da década de 1950 e integrado por negros, estudantes, ativistas contra a guerra no Vietnã etc. ao associativismo voluntário. Para a autora, os contestadores civis que se manifestavam nos Estados Unidos formavam entre si uma "derradeira forma de associação voluntária" (ARENDT, 1972b, p. 96), destacada por Tocqueville ao discorrer sobre o hábito da associação como uma das características da vida pública norte-americana que mais lhe havia chamado a atenção. "Os poucos capítulos que ele [Tocqueville] devota a elas [as associações voluntárias] ainda são de longe o melhor da escassa literatura sobre o tema", reconhece (ARENDT, 1972, p. 94).

Arendt define os contestadores civis como minorias organizadas que unem em torno de uma opinião comum para fazer frente a alguma política governamental imposta como o desejo da maioria. Assim, o modus operandi dessas minorias ocorreria da maneira como havia descrito Tocqueville, no primeiro volume da Democracia...: "primeiro, para constatar seu número e descobrir o império moral da maioria; o segundo objetivo [...] é descobrir os argumentos mais apropriados a impressionar a maioria" (TOCQUEVILLE, 1992a, p. 218).

$\mathrm{Na}$ tradição das associações voluntárias que Tocqueville havia descrito, esses grupos de contestadores civis eram integrados, na visão de Arendt, por indivíduos movidos pelo espírito público e pela responsabilidade cívica, ao confrontar publicamente o Poder Executivo norteamericano, denunciando-o pela guerra "ilegal e imoral" contra o Vietnã, por atentar contra as liberdades asseguradas pela Primeira Emenda (entre elas, a de expressão, imprensa e de livre associação), ferir a autonomia das universidades, entre outros abusos (ARENDT, 1972b, p. 93) . Ao exercer o seu direito de dissidência, eles demonstravam publicamente o seu comprometimento com o mundo público, denunciando os descaminhos da república norte-americana e confrontando 
autoridades que haviam perdido legitimidade na medida que colocavam em xeque as bases que sustentavam a aliança do pacto original do país, ao exarcebar as suas atribuições constitucionais.

\section{Considerações finais}

Conforme se demonstrou, Alexis de Tocqueville e Hannah Arendt apresentam muitas afinidades na forma de pensar a política e as potencialidades da ação coletiva. $\mathrm{Na}$ análise que cada um faz sobre as Revoluções Americana e Francesa, ressalta-se a preocupação comum em pensar em uma forma de institucionalização do poder que preserve a liberdade - concebida por ambos os autores, acima de tudo, como liberdade política - e assegure a participação popular na condução da vida pública.

Também deve-se ressaltar que a preocupação mútua dos dois autores com a estabilidade e a durabilidade das instituições políticas não subordina a ação política ao campo de atuação do governo. Por isso, ele realçam uma esfera pública descentralizada, em que o poder seja o mais disseminado e pulverizado possível. Daí a ênfase nas associações voluntárias como formas de organização política que não se restringem às instituições do Estado.

Com relação às formas de autogoverno destacadas por ambos - as comunas e os conselhos populares -, estas não devem ser concebidas como modelos prontos para ser aplicados à realidade, o que, aliás, contrariaria os próprios pressupostos teóricos básicos de Arendt, a saber, "aquele que afirma a primazia da ação sobre as ideias” (ADVERSE, 2012, p. 421). Já Tocqueville alerta na introdução do primeiro volume da Democracia... que, ao detalhar o modelo sociopolítico dos EUA da década de 1830, jamais pretendeu que ele pudesse ser replicado integralmente em outros locais (TOCQUEVILLE, 1992 a, p..15)., já que cada comunidade política conta com suas particulidades próprias, referentes às suas tradições, à sua história e à sua cultura. Assim, essas formas de autogoverno tão enaltecidas por ambos devem ser vistas, antes de tudo, como marcos inspiradores para pensar em alternativas políticas que abram brechas a uma efetiva participação popular e que confrontem os esgotados modelos contemporâneas das democracias representativas, nas quais o povo se vê cada vez mais distanciado do centro das decisões políticas.

\section{REFERÊNCIAS}

ADVERSE, Helton. Uma república para os modernos. Arendt, a secularização e o republicanismo. Filosofia Unisinos, v. 13, n. 1, p. 39-56, jan./abr. 2012.

ARENDT, Hannah. Ação e busca da felicidade. Organização e notas de Heloisa Murgel Starling. Rio de Janeiro: Bazar do Tempo, 2018.

ARENDT, Hannah. Correspondance - 1939-1968 [entre Hannah Arendt e Heinrich Blücher]. Introduite et anotté par Lotte Köhler. Paris: Calman-Lévy, 1996.

ARENDT, Hannah. On revolution. London: Peguin Books, 1990. 
ARENDT, Hannah. On violence. In: Crisis of the republic. New York: Harcourt Brace \& Company, 1972.

ARENDT, Hannah. The origins of totalitarianism. New York: Harcourt Brace \& Company, 1973.

ARENDT, Hannah. The buman condition. 2 ed. Chicago: The University of Chicago Press, 1998.

ARON, Raymond. As etapas do pensamento sociológico. São Paulo: Martins Fontes, 2011.

BENOIT, Jean-Louis. Tocqueville - un destin paradoxal . Paris: Éditions Perrin, 2013.

BERLIN, Isaiah. Dois conceitos de liberdade. In: Quatro ensaios sobre a liberdade. Brasília (DF): Editora da Universidade de Brasília, 1981.

BIGNOTTO, Newton. Hannah Arendt e a revolução. O que nos faz pensar, Rio de Janeiro, 2011, p. $59-75$.

CANOVAN, Margaret. Hannah Arendt - A reinterpretation of her political thought. New York: University of Cambridge, 1992.

CONSTANT, Benjamin. De la liberté des anciens comparée à celle des modernes. Paris: Berg International, 2016.

CHAVES, Rosângela. O dia de glória chegou: revolução, opinião e liberdade em Tocqueville e Arendt. Goiânia, 2018. 495f. Tese (Doutorado em Filosofia) - Programa de Pós-graduação em Filosofia, Universidade Federal de Goiás, Goiânia, 2018.

KING, Richard H. Arendt and America. Chicago and London: The University of Chicago Press, 2015.

LAMBERTI, Jean-Claude. Tocqueville et les deux démocraties. Paris: PUF, 1983.

LHOYD, Margie. Tocqueville's shadow: Hannah Arendt's liberal republicanism. Review of politics, Notre Dame, v. 57, n. 1, p. 31-58, 1995.

MAYER, J.P. Prophet of the mass age - A study of Alexis de Tocqueville. London: J.M. Dent and Sons Ltd, 1939.

PITKIN, Hanna Fenichel. The attack of the blob - Hannah Arendt's conception of the social. Chicago: The University of Chicago Press, 1998.

POIZAT, Jean-Claude. Hannah Arendt - Une introduction. Paris: Agora, 2013.

TOCQUEVILLE, Alexis de. Oeuvres complètes IX. Correspondance d'Alexis de Tocqueville et d'Arthur de Gobineau. 4. ed. Paris: Gallimard, 1959.

TOCQUEVILLE, Alexis de. De la démocratie en Amerique. In: Oeuvres, II. Paris: Éditions Gallimard, 1992a. v.1. (Bibliothèque de la Pléiade).

TOCQUEVILLE, Alexis de. De la démocratie en Amerique. In: Oeuvres, II. Paris: Éditions Gallimard, 1992b. v.2. (Bibliothèque de la Pléiade).

TOCQUEVILLE, Alexis de. L’Ancien Régime et la Révolution (1856). In: Oewvres, III. Paris: Éditions Gallimard, 2004. (Bibliothèque de la Pléiade).

VILLA, Dana. Public freedom. New Jersey: Princeton University Press, 2008. 
VILLA, Dana. Tocqueville and civil society. In: WELCH, Cheryl (Ed.). The Cambridge Companion to Tocqueville. New York: Cambridge University Press, 2006.

YOUNG-BRUEHL, Elisabeth. Hannah Arendt - For love of the world. New Haven and London: Yale University Press, 1982. 